\title{
Canadian Guidelines on Opioid Use Disorder Among Older Adults
}

Launette M. Rieb, MD, MSc, CCFP(AM), FCFP, DABAM, FASAM ${ }^{1}$, Zainab Samaan, $\mathrm{MBChB}$, MRCPsych (UK), $\mathrm{PhD}^{2}$, Andrea D. Furlan, MD, $\mathrm{PhD}^{3}$, Kiran Rabheru, MD, CCFP, FRCP 4 , Sid Feldman, MD, CCFP(COE), FCFP 5 , Lillian Hung, RN, $\mathrm{PhD}^{6}$, George Budd, PharmD, BSc, Pharm, RPh ${ }^{7}$, Douglas Coleman, MD, CCFP, FASAM, DABAM ${ }^{8}$

(for the Canadian Coalition for Seniors' Mental Health)

${ }^{1}$ Department of Family Practice, University of British Columbia, Vancouver, BC; ${ }^{2}$ Department of Psychiatry, McMaster University, Hamilton, ON; ${ }^{3}$ Department of Medicine, University of Toronto, Toronto, ON; ${ }^{4}$ Department of Psychiatry, University of Ottawa, Ottawa, ON; ${ }^{5}$ Department of Family and Community Medicine, University of Toronto, Toronto, ON; ${ }^{6}$ Canadian Gerontological Nurses Association, Toronto, ON; ${ }^{7}$ Clinical Pharmacist, Vancouver, BC; ${ }^{8}$ Family Physician (in private practice), Comox, $B C$

https://doi.org/10.5770/cgj.23.420

\section{ABSTRACT}

\section{Background}

In Canada, rates of hospital admission from opioid poisoning have been higher for older adults $(>65)$ than younger adults for decades, only recently surpassed by younger non-medical opioid users. Opioid use disorder (OUD) among older adults is a growing concern. In response, Health Canada commissioned the Canadian Coalition of Seniors' Mental Health to create guidelines for the prevention, screening, assessment, and treatment of OUD in older adults.

\section{Methods}

A systematic review of English language literature from 2008-2018 regarding OUD in adults was conducted. Previously published guidelines were evaluated using AGREE II, and key guidelines updated using ADAPTE method, by drawing on current literature. Recommendations were created and assessed using the GRADE method.

\section{Results}

Thirty-two recommendations were created. Prevention recommendations: it is key to prioritize non-pharmacological and non-opioid strategies to treat acute and chronic noncancer pain. Assessment recommendations: a comprehensive assessment is important to help discern contributions of other medical conditions. Treatment recommendations: buprenorphine is first line for both withdrawal management and maintenance therapy, while methadone, slow-release oral morphine, or naltrexone can be used as alternatives under certain circumstances; non-pharmacological treatments should be offered as an integrated part of care.

\section{Conclusion}

These guidelines provide practical and timely clinical recommendations on the prevention, assessment, and treatment of OUD in older adults within the Canadian context.

Key words: opioids, opioid dependence, opioid use disorder, substance use disorder, substance abuse, older adult, geriatric, systematic review, guideline

\section{INTRODUCTION}

According to the World Health Organization (WHO), people over the age of 50 accounted for $39 \%$ of deaths from drug use worldwide by 2015, and of those deaths in older adults (age $\geq 65$ ), approximately $75 \%$ were linked to the use of opioids. $(1,2)$ Despite these numbers, there is a paucity of data about the many ways opioids specifically affect older adults and about how to care for those who develop an addiction, also referred to as an opioid use disorder (OUD).(3)

There are two primary cohorts of older adults who develop OUD. The first group is made up of those who have been exposed to opioids for many years through drug experimentation, often beginning in adolescence. Some have been identified with and treated for an OUD, and many have had adverse health consequences.(4-6) The second group of older adults who may develop OUD is made up of those individuals who were prescribed opioids by a health-care provider for a pain condition. ${ }^{(7,8)}$ Some of these individuals may have turned to the illicit market in order to maintain an ongoing supply of opioids following discontinuation of their prescription by a health-care professional. Opioid withdrawal pain 


\section{RIEB: OPIOID USE DISORDER GUIDELINES}

can perpetuate the unintended long-term use of opioids for chronic non-cancer pain or due to an OUD, with underlying drivers being opioid-induced hyperalgesia and withdrawalassociated injury-site pain. (9,10-12) $^{(1)}$

In Canada, $43.9 \%$ of adults $>55$ years of age have used a prescription opioid and $1.1 \%$ of that group have done so daily (or almost daily) in the last year. ${ }^{(13)}$ Though the proportion of people starting opioid therapy in Canada has trended down from 2013 to 2018, those over 65 have consistently received more new opioid prescriptions and have a higher proportion that go on to long-term opioid therapy (24.8\%) than any other

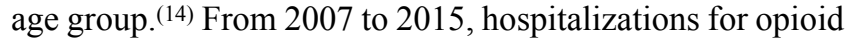
overdose (referred to as poisonings) in Canada were consistently higher in older adults than in any other age cohort: At over 20 per 100,000, older-adult admissions are almost double that of 15 to 24 -year-olds, and represent $30 \%$ of all admissions to hospital for opioid poisoning.(15) Only recently by 2017 have younger adults in Canada started to equal and just surpass older adults in hospitalizations related to opioid poisonings. Most opioid poisonings in adults in Canada are accidental; however, $30 \%$ are intentional.(16) A recent study found that in older adults, opioid misuse was associated with increased odds of suicidal ideation. ${ }^{(17)}$

According to a US national survey in 2016, $0.8 \%$ of adults surveyed met Diagnostic and Statistical Manual of Mental Disorders Fourth Edition (DSM-IV) criteria for OUD in the past year. ${ }^{(18)}$ There are no comparable Canadian studies that use DSM criteria. However one used WHO criteria and estimated a past year prevalence of OUD in Canadian adults to be $0.9 \%$ for drug abuse, and $0.5 \%$ for drug dependence. Yet reporting of prevalence data is lacking specific to those over 65 using opioids. ${ }^{(19,20)}$

OUD may present more subtly in older adults than their younger counterparts and require a more nuanced approach. (21) OUD may overlap with physiologic tolerance alone and may be mistaken for or masked by other medical conditions. Consequences from opioid use may not be recognized in older adults who have stopped work and who have restricted social networks. Social stigma and cognitive impairment may each play a role in under-identification.

Adults entering older age are having an effect on the changing demographics of substance use and the need for treatment, its utilization, and its cost. For example, one study from New York City found that, as of 2012, adults $>60$ years of age comprised $13.1 \%$ of those in opioid treatment programs, up from $1.7 \%$ in 2006.(22) This study also noted a shift from illicit drugs to those obtained by prescription as the primary type of opioid used. Additionally, when compared to their younger counterparts, older US veterans with OUD have higher rates of comorbid mood disorder, post-traumatic stress disorder, hepatitis $\mathrm{C}$, human immunodeficiency virus, and chronic pain, including neuropathy, which has notably increased the cost of care. ${ }^{(23)}$
The purpose of this article is to outline the issues facing older adults with, or at risk for, an OUD, and to provide a summary of recommendations for the prevention, screening, assessment, and treatment of an OUD in those $\geq 65$ years of age. The full guidelines can be accessed electronically (www.ccsmh.ca).

\section{METHODS}

An experienced librarian and research assistants conducted a systematic literature search for relevant studies related to opioid use and opioid use disorder in adults and older adults. The databases searched included the Cochrane Library, EMBASE, PsychInfo, International Guideline Library, and PubMed. Included studies for the recommendations were restricted to human and written in English, with publications dates from 2008 through March 2018. The date limitation of the literature was decided a priori based on the changes observed in the last decade related to the opioid crisis in Canada. More recent literature was included in the introduction and discussion.

An interdisciplinary guideline development committee was set up through the Canadian Coalition of Seniors' Mental Health, consisting of two addiction medicine specialists, two psychiatrists, a physical medicine and rehabilitation specialist, a nurse practitioner, a pharmacist, a family physician with expertise in care of the elderly, as well as a person with lived experience. The committee members identified the top quality guidelines on OUD published using the Appraisal of Guidelines for Research \& Evaluation Instrument (AGREE II). ${ }^{(24)}$ We then modified the existing key guidelines using the ADAPTE collaboration process ${ }^{(25)}$ in order to customize the selected guidelines for older adults and the Canadian context. We formulated questions in the PICOT format (Population, Intervention, Comparator, Outcome and Time) as a working group, and populated the questions with answers obtained from the previously chosen key guidelines, then supplemented this information with evidence from current literature.

Working group members drafted recommendations and provided the evidence for each of the recommendations. The person with lived experience provided views and preferences of the target population. The draft recommendations were then reviewed by the whole working group, feedback integrated, so that the final wording of each recommendation was the result of full consensus. Each recommendation was then evaluated using the GRADE system (Grades of Recommendation Assessment, Development, and Evaluation). (26,27) GRADE scores the quality of the evidence as high, moderate, low or very low. It was agreed that "low" and "very low" scores would be amalgamated as "low". The strength of the recommendations was scored as strong or weak. ${ }^{(26,27)}$ We continued to discuss each recommendation and evaluation until we reached $100 \%$ consensus on each recommendation. The final recommendations were then sent for external peer review. The working group members integrated the majority of the comments from external reviewers into the guidelines after discussion. 


\section{RESULTS}

\section{Selection of the Previous Guidelines for Adaptation}

Only one previous guideline published by the Royal College of Psychiatrists (United Kingdom) in the last 10 years for the prevention, assessment, and treatment of OUD specific to older adults was identified in the English language literature searched. ${ }^{(28)}$ We chose to include this guideline for its direct relevance to older adults, despite a low-quality rating on the AGREE II tool.

We closely reviewed the top four rated OUD guidelines focused on adults in general (not just older adults) published in the last 10 years. ${ }^{(29-32)}$ We chose the US Veterans' Affairs and Department of Defense's guideline (2015) as the best rated guideline to use as a starting point, per the AGREE II tool. We also relied on elements of the Canadian Clinical Practice Guideline for Opioid Use Disorder for its applicability to our local context. ${ }^{(32)}$

Recommendations from less robust guidelines and clinical practice tips on OUD were considered when the selected guidelines did not address an issue fully or supporting evidence was needed.(33-41) We considered costs, benefits, and harms when we were drafting the recommendations.

No published randomized, controlled trials were identified on the prevention, assessment, or treatment of OUD in older adults. Therefore, the main evidence used to generate the recommendations was based on the above guidelines, along with systematic and narrative reviews on older adults since 2015.(42-49) In addition, numerous clinical and observational studies extrapolated from younger adults, some observational cohorts in older adults, as well as clinical expertise, informed these guidelines. For the section on prevention, key Canadian and US guidelines were identified for the treatment of chronic non-cancer pain $(\mathrm{CNCP}){ }^{(50-52)}$

\section{RECOMMENDATIONS}

\section{Prevention of Opioid Use Disorder Among Older Adults}

To curb opioid poisonings and the development of OUD, measures need to be implemented for both primary and secondary prevention. These issues are outlined in the questions (A \& B) and addressed in the recommendations (1-9) listed below.

\section{Question A: In older adults, what measures can} reduce the risk of developing an OUD?

\section{Recommendation 1}

In order to avoid the risk of developing an OUD, older adults with acute pain in whom opioids are being considered should receive the lowest effective dose of the least potent immediate release opioid for a duration of $\leq 3$ days and rarely $>7$ days. (44,51-55) GRADE Quality: Moderate; Strength: Strong

\section{Recommendation 2}

In most circumstances, avoid prescribing opioids for older adults with CNCP. For severe pain that is not responsive to non-opioid therapy in patients without a history of substance use disorder and without active mental illness, a trial of opioid treatment may be considered. Consider obtaining a second opinion before prescribing long-term opioid therapy. After explaining the risks and benefits to the patient, prescribe only in accordance with published guidelines for adults, initiate and maintain opioids at lower doses than for younger adults, and discontinue if function does not improve or if adverse effects arise. ${ }^{(50,51,53,56-58)}$ GRADE Quality: Moderate; Strength: Strong

\section{Recommendation 3}

Patients and their families should be advised to store opioids safely, never to share their medication, and to return unused medication to the pharmacist for disposal. ${ }^{(50,59,60)}$ GRADE Quality: Low; Strength: Strong

\section{Recommendation 4}

Pharmacists and nursing staff are advised to inform the prescriber if there are concerns with co-prescribing, adherence to treatment, or intoxication. ${ }^{(61,51)}$ GRADE Quality: Low; Strength: Strong

Question B: In older adults with or at risk for an OUD, what preventive measures can reduce the risk of opioid overdose?

\section{Recommendation 5}

In older adults with polypharmacy or comorbidities that increase the risk of opioid overdose (e.g., benzodiazepine use, renal failure, sleep apnea), the lowest effective opioid dose should be used and tapering the opioid and/or other medications should be considered. (50,51,62-64) GRADE Quality: Moderate; Strength: Strong

\section{Recommendation 6}

Once the decision is made to reduce the opioid dose, a slow outpatient tapering schedule (e.g., 5\% drop every 2-8 weeks with rest periods) is preferable to more rapid tapering. A faster taper schedule may be attempted under special circumstances of medical need, if the patient is in a treatment setting with medical supervision. ${ }^{(32,9,65-67)}$ GRADE: Quality: Low; Strength: Weak

\section{Recommendation 7}

Dispense naloxone kits to anyone using opioids regularly for any reason (CNCP, OUD, etc.), and train household members and support staff on use. ${ }^{68,69)}$ GRADE Quality: Low; Strength: Weak

\section{Recommendation 8}

Include skilled pharmacists and/or nurses on teams to educate patients on appropriate use of opioids and other medications. (70-72) GRADE Quality: Low; Strength: Weak 


\section{Recommendation 9}

Older adults with, or at risk for, an OUD should be given advice on strategies to reduce the risk of opioid overdose, and information on supervised consumption sites, if available in the community. ${ }^{(73-75)}$ GRADE Quality: Moderate; Strength: Strong

\section{Screening for and Assessment of Opioid Use Disorder Among Older Adults}

Screening and assessment are the starting points for care of a person with an OUD, and many effective approaches to both exist for adults. ${ }^{(76)}$ Listed below are questions (C-E) along with recommendations (10-12) for screening and assessment of OUD specific to older adults:

Question C: In older adults, when and how should one screen for an OUD?

\section{Recommendation 10}

Older adults should be screened for an OUD using validated tools, if appropriate (e.g., CAGE-AID, ASSIST, PDUQp, ORT, POMI, COMM). Medication reviews and urine drug screens should be utilized if the patient is taking opioids for CNCP or an OUD. ${ }^{(30,41,77-80)}$ GRADE Quality: Low; Strength: Strong

Question D: In older adults at risk for an OUD, what are the elements of assessment?

\section{Recommendation 11}

Identify a diagnosis of an OUD through completion of a comprehensive assessment, including substance use, medical, pain, psychiatric, cognitive, and psychosocial history within a cultural context, and conduct a brief functional assessment. The use of validated assessment tools may be useful in this process. In addition, a detailed physical examination must be conducted, with an emphasis on signs of intoxication or withdrawal and the sequelae of substance use. Laboratory and other investigations (including urine drug tests) should be performed as appropriate for the medical conditions identified. Reassessment is essential and should be conducted episodically throughout long-term care. ${ }^{(28,33,41,76,81,82)}$ GRADE Quality: Moderate; Strength: Strong

Question E: In older adults with or at risk for an OUD, what considerations are important to patients during the assessment process?

\section{Recommendation 12}

A full explanation of findings and diagnosis must be shared with the patient and, if appropriate, caregivers. Therapeutic optimism should be provided (i.e., hope given that addiction is a treatable disorder and that older adults, and especially older women, typically have better treatment outcomes than younger adults).(42,83) GRADE: Consensus

\section{Treatment of Opioid Use DisorderAmong Older Adults}

\section{Pharmacological Treatment}

Issues related to pharmacological treatments are asked in questions (F-H) and answered in recommendations (13-26) listed below.

Question F: In older adults with an OUD, what approaches and medications are safe and effective for opioid withdrawal management?

\section{Recommendation 13}

Opioid withdrawal management should only be offered in the context of connection to long-term addiction treatment. (30-32,41,43-47,84-86) GRADE Quality: Moderate; Strength: Strong

\section{Recommendation 14}

Induction onto an opioid agonist is recommended over a nonopioid treatment withdrawal management in older adults with an OUD. If a trial of tapering is attempted, there should be the option to initiate longer-term opioid agonist therapy or opioid antagonist therapy. ${ }^{(30-32,41,43-47,84-91)}$ GRADE Quality: Moderate; Strength: Weak

\section{Recommendation 15}

Buprenorphine-naloxone should be considered first line for opioid withdrawal management in older adults. Methadone is an alternative that may be used, however consider the added risk of adverse events. ${ }^{(30-32,44,91-93)}$ GRADE Quality: Moderate; Strength: Weak

\section{Recommendation 16}

For symptom control during opioid withdrawal management, adjuvant medications can be used in a time-limited fashion, but with caution due to medical comorbidities, side effect risk,

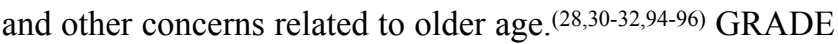
Quality: Moderate; Strength: Weak

\section{Question G: What medications and protocol} adjustments are safe and effective in the treatment of an OUD in older adults to improve outcomes?

\section{Recommendation 17}

Buprenorphine maintenance should be considered a first-line treatment for an OUD in older adults. ${ }^{28,30-33,43-45,47,92,93,97-108)}$ GRADE Quality: Moderate; Strength: Strong

\section{Recommendation 18}

Methadone maintenance treatment may be considered for those older adults who cannot tolerate buprenorphine maintenance or in whom it has been ineffective. $(4,22,28-33,41-45,101,109-114)$ GRADE Quality: Moderate; Strength: Strong

\section{Recommendation 19}

If renal function is adequate, daily witnessed ingestion of slow-release oral morphine may be considered with caution 


\section{RIEB: OPIOID USE DISORDER GUIDELINES}

for those older adults in whom buprenorphine and methadone maintenance have been ineffective or could not be tolerated. Careful supervision of initiation onto short-acting morphine first is recommended, prior to transition to maintenance with the long-acting 24-hour formulation. ${ }^{32,99,115)}$ GRADE Quality: Low; Strength: Weak

\section{Recommendation 20}

For older adults with an OUD for whom opioid agonist treatment is contraindicated, unacceptable, unavailable, or discontinued and who have established abstinence for a sufficient period of time, naltrexone may be offered. $(30,32,43-45,47,100,101,116-120)$ GRADE Quality: Moderate; Strength: Weak

\section{Recommendation 21}

Offer medications for an OUD in the context of connection to long-term addiction, mental health, and primary care treatment, where careful monitoring and dose titration can occur. (18,28,31,39,44,121) GRADE Quality: Moderate; Strength: Strong

\section{Recommendation 22}

Advise patients that the use of alcohol, benzodiazepines, and other sedative-hypnotics is hazardous when combined with opioid agonist treatment. If the older adult is living in the community and is already physiologically dependent on one of these substances, then slow tapering of the substance(s) (to elimination, if possible), rather than abrupt cessation, is recommended. If the patient is in hospital, residential treatment, or a longterm care setting and medically managed by an experienced provider, detoxification can progress more rapidly, concurrent with the initiation or stabilization on medications for OUD. (30,32,36,45,122,123) GRADE Quality: Moderate; Strength: Strong

\section{Recommendation 23}

Early take-home dosing for buprenorphine maintenance treatment may be considered, including home induction in patients who are low risk, if they find it difficult to attend the office in withdrawal and if the patient has social supports at home. This approach should not be considered for methadone initiation unless supervised (e.g., reliable caregiver or medical personal administration). ${ }^{(32,124)}$ GRADE Quality: Low; Strength: Weak

Question H: In older adults, compared with younger adults, what dose/protocol adjustments are needed when initiating or maintaining medications to treat an OUD?

\section{Recommendation 24}

Reduce initial doses of medications for treatment of an OUD (e.g., by $25-50 \%$ ); slow dose escalation frequency (e.g., by $25-50 \%$ ); use the lowest effective dose to suppress craving, withdrawal symptoms and drug use; and monitor closely (especially for sleep apnea, sedation, cognitive impairment, and falls with opioid agonists).(28,43,124-128) GRADE Quality: Low; Strength: Strong

\section{Recommendation 25}

The threshold to admit an older adult with social, psychological, or physical comorbidities to either residential or hospital care for opioid withdrawal management or induction onto medications for an OUD should be lower than for a younger adult.(41,129) GRADE: Quality: Moderate; Strength: Strong

\section{Recommendation 26}

In older adults on medication for an OUD requiring management of mild-to-moderate acute pain or CNCP, non-medication and non-opioid strategies are recommended. For those on an opioid agonist for an OUD who have severe acute pain that has been unresponsive to non-opioid strategies, a short-acting opioid may be considered for a short duration (1-7 days) along with a taper, if necessary (1-7 days). ${ }^{30,32,36,39,50,51,62,130-132)}$ GRADE Quality: Moderate; Strength: Weak

\section{Other Comments on Medications for OUD}

In younger adults, for the palliative end of the OUD spectrum in whom all other modalities have been unsuccessful, there is currently available in Canada injectable opioid agonist treatment (iOAT). No data on iOAT in older adults were identified. The risk of adverse events with injectable medications rises with age, as does immunosuppression and mobility issues for accessing the three-times-daily visit to a clinic needed for iOAT. BC is currently the only province providing and paying for iOAT, and the cost is higher than with all other opioid agonist and antagonist treatments. Due to all of the above issues, we cannot endorse iOAT treatment in older adults at this time and thus have not included it in these guidelines.

\section{Psychosocial Treatment}

Although robust data on behavioural interventions in older adults with OUD are lacking, an understanding of the importance of incorporating psychosocial supports is clear: Older adults may have an accumulation of losses (job, spouse, family, friends, role, home), and may struggle with lack of social support. ${ }^{133,134)}$ The key question (Question I) regarding psychosocial interventions in older adults with an OUD is outlined below, along with related recommendations $(27-31)$.

Question I: In older adults, what psychosocial interventions are effective in the treatment of an OUD to improve outcomes?

\section{Recommendation 27}

Psychosocial interventions should be offered concurrently with medications for an OUD, at a pace appropriate for age and patient needs, but they should not be viewed as a mandatory requirement for accessing pharmacotherapy. ${ }^{(135-139)}$ GRADE Quality: Moderate; Strength: Strong 


\section{RIEB: OPIOID USE DISORDER GUIDELINES}

\section{Recommendation 28}

Contingency management may be offered as part of opioid treatment programs and used if accepted by the patient. ${ }^{(140-147)}$ GRADE Quality: Moderate; Strength: Weak

Question J: For older adults with an OUD, what are the treatment considerations for special populations (specifically Indigenous peoples)?

\section{Recommendation 29}

Traditional healing practices used by Indigenous communities can be integrated with buprenorphine treatment to improve outcomes for an OUD. ${ }^{(148)}$ GRADE Quality: Low; Strength: Weak

\section{Setting}

Setting can refer to treatment setting and also the living situation of the older adult.

Question K: For older adults with an OUD, what specific treatment recommendations are suggested for non-community-based facilities?

\section{Recommendation 30}

If experienced, clinicians may manage older adults with a mild-to-moderate OUD; however, for patients with more severe or complex disorders, it is recommended that personnel or teams with advanced substance use disorder management skills be accessible to support clinicians and to enhance their capacity to care for patients in all settings. The threshold for an admission to hospital or drug and alcohol treatment facility under the care of an Addiction Medicine Specialist is lower than for younger adults, and closer follow-up is needed on discharge to ensure appropriate community-based support. (44,149-151) GRADE Quality: Moderate; Strength: Strong

\section{Recommendation 31}

Older adults with an OUD who are admitted to a hospital, drug and alcohol treatment facility, or non-medical facility with access to medical care (e.g., prisons and shelters) should be offered opioid agonist treatment at the onset of withdrawal (advisable within 1-3 days), with bridging pharmacological treatment on discharge with confirmed transfer of care. (31,98,109,152-159) GRADE Quality: Moderate/Strength: Strong

Question L: For older adults with an OUD, what systemic factors support recovery?

\section{Recommendation 32}

The cost of medically-recommended pharmacological and non-pharmacological treatment for an OUD in older adults should be covered by the public health plan. $(28,31,32,36,160)$ GRADE Quality: Moderate; Strength: Strong

\section{DISCUSSION}

No previous guidelines or clinical trials for the prevention, screening or management of OUD have been undertaken in adults over 65 despite the increasing prevalence of OUD in this age group. Our guidelines represent a systematic effort to identify evidence from literature, taking into consideration the context, the expertise of individuals working with older adults, the input from individuals with lived experience, and the multidisciplinary guideline team. These guidelines provide 32 recommendations covering aspects of opioid management from prevention, screening, assessment, pharmacological treatment, psychosocial interventions, treatment setting, and steps to recovery. Many of the recommendations are in alignment with the other two recent Canadian guidelines on OUD treatment in adults. $(32,161)$

The challenges and limitations in writing these guidelines were many, most important of which was the lack of direct evidence to inform the guidelines of the efficacy or effectiveness of current treatment approaches in this population. Other limitations include lack of a consistent definition for older adults and successful treatment outcome measures for OUD. Finally, there are limited data and empirical evidence for the management of OUD in special populations of older adults related to sex, gender, and ethnic group.

Studies with a focus on older adults are needed to provide empirical evidence for the effectiveness of pharmacological and psychosocial treatments. The deliberate inclusion of subgroups in these studies will provide data for future guidelines to improve their external validity. Future studies to define meaningful and patient-centered treatment outcomes targets are needed. Also, the role of other interventions that are less studied, including self-help groups, is yet to be delineated. Canadian-based data are needed on the rates of opioid use and OUD in older adults, as well as rates of overdose and mortality, in order to design targeted prevention strategies and test the effectiveness of OUD treatment and opioid overdose mitigation.

\section{Facilitators and Barriers for the Application of These Recommendations}

In Canada, the need for expanded resources for treatment of older adults with OUD will likely rise in the coming years. Evidence-based treatment for OUD in adults in general is costeffective and decreases both morbidity and mortality. ${ }^{(162)}$ The lifetime savings to provincial and national health care based on this model could be substantial. All components of the Canadian health-care system must prepare to provide addiction treatment to older adults, including those affected by an OUD.

The uptake of these guidelines will be monitored through tracking CCSMH website visits, orders of print version, distribution of office handouts, and journal article reads. There are plans to update the guidelines approximately every five years, as needed, if new literature becomes available that may significantly change management. 


\section{CONCLUSION}

Older adults are susceptible to adverse health consequences of opioid use. There is a growing need for opioid management guidelines for older adults as the population in Canada ages. The current recommendations are intended to provide healthcare workers and policy-makers with evidence-informed, clinically relevant direction and advice on the prevention, screening, assessment, and treatment of OUD in older adults. We hope practitioners will find them both a practical and useful clinical aide, and that community members will find them a helpful education resource. The expanded version of these guidelines can be accessed electronically (www.ccsmh.ca).

\section{ACKNOWLEDGEMENTS}

Funding was provided by Health Canada, Substance Use and Addictions Program. In addition, we would like to thank the Canadian Centre of Substance Use and Addiction (CCSA) and the Behavioral Supports Ontario Substance Use Collaborative for their support, Dr. Meldon Kahan for early guidance, and for external review along with Dr. Ashok Krishnamoorthy, and Dr. John Fraser. Thanks goes to Tonya Mahar for her assistance with literature searches. Finally, we would like to acknowledge the continued dedication of our steering committee, particularly the Co-Lead Dr. David Conn, along with the contribution of our Director, Claire Checkland, and our coordinators: Indira Fernando, Natasha Kachan, and MarcAndré LeBlanc.

\section{DISCLAIMER}

This publication is intended for information purposes only, and is not intended to be interpreted or used as a standard of medical practice. Best efforts were used to ensure that the information in this publication is accurate; however, the publisher and every person involved in the creation of this publication disclaim any warranty as to the accuracy, completeness or currency of the contents of this publication. This publication is distributed with the understanding that neither the publisher nor any person involved in the creation of this publication is rendering professional advice. Physicians and other readers must determine the appropriate clinical care for each individual patient on the basis of all the clinical data available for the individual case. The publisher and every person involved in the creation of this publication disclaim any liability arising from contract, negligence, or any other cause of action, to any party, for the publication contents or any consequences arising from its use.

\section{CONFLICT OF INTEREST DISCLOSURES}

The project was funded by Health Canada (Substance Use and Addictions Program). The funder had no role in the creation or approval of the recommendations. Authors received an honorarium for their work. A rigorous process was undertaken to ensure that members of the working group did not have any significant conflict of interest.

\section{REFERENCES}

1. Degenhardt L, Hall W. Extent of illicit drug use and dependence, and their contribution to the global burden of disease. The Lancet. 2012;379(9810):55-70. 2. UNODC. 2019 World Drug Report. Executive Summary: Conclusions and Policy Implications. New York, NY: United Nations; 2018. Available from: https://wdr.unodc.org/wdr2019/prelaunch/WDR19_Booklet _1_EXECUTIVE_SUMMARY.pdf

3. American Psychiatric Association. Diagnostic and statistical manual of mental disorders, 5th ed. Arlington, VA: American Psychiatric Publishing; 2013.

4. Grella CE, Lovinger K. 30-year trajectories of heroin and other drug use among men and women sampled from methadone treatment in California. Drug Alcohol Depend. 2011;118(2-3): 251-58. Epub 2011/05/10.

5. Hser YI, Huang D, Chou CP, et al. Trajectories of heroin addiction: growth mixture modeling results based on a 33-year follow-up study. Evaluation Rev. 2007;31(6):548-63. Epub 2007/11/08.

6. Lofwall MR, Brooner RK, Bigelow GE, et al. Characteristics of older opioid maintenance patients. J Subst Abuse Treat. 2005;28(3):265-72. Epub 2005/04/29.

7. Jinks MJ, Raschko RR. A profile of alcohol and prescription drug abuse in a high-risk community-based elderly population. DICP. 1990;24(10):971-75. Epub 1990/10/01.

8. Kalapatapu RK, Sullivan MA. Prescription use disorders in older adults. Am J Addict. 2010;19(6):515-22. Epub 2010/10/21.

9. Rieb LM, Norman WV, Martin RE, et al. Withdrawal-associated injury site pain (WISP): a descriptive case series of an opioid cessation phenomenon. Pain. 2016;157(12):2865-74. Epub 2016/09/07.

10. Rieb LM, Norman WV, Martin RE, et al. Linking opioidinduced hyperalgesia and withdrawal-associated injury site pain. PAIN Rep. 2018;3(e648):1-4

11. Rivat C, Ballantyne J. The dark side of opioids in pain management: basic science explains clinical observation.. PAIN Rep. 2016;1(2):e570.

12. Ballantyne JC, Sullivan MD, Koob GF. Refractory dependence on opioid analgesics. Pain. 2019;160(12):2655-60.

13. Canadian Centre on Substance Use and Addiction (CCSA). Substance use in Canada: improving quality of life substance use and aging. Ottawa, ON: Canadian Centre on Substance Use and Addiction; 2018. Available from: http://www.ccsa .ca/Resource\%20Library/CCSA-Substance-Use-and-Aging -Report-2018-en.pdf

14. Canadian Institute for Health Information (CIHI). Opioid prescribing in Canada: how are practices changing? Ottawa, ON: The Institute; 2019. Available from: https://www.cihi.ca/ sites/default/files/document/opioid-prescribing-canada-trendsen-web.pdf

15. Canadian Institute for Health Information (CIHI). Hospital morbidity database. Ottawa, ON: The Institute; 2018. Available from: https://www.cihi.ca/en/hospital-morbidity-database 


\section{RIEB: OPIOID USE DISORDER GUIDELINES}

16. Canadian Institute for Health Information. Opioid-related harms in Canada. Ottawa, ON: CIHC; 2018. Available from: https:// www.cihi.ca/sites/default/files/document/opioid-related-harms -report-2018-en-web.pdf

17. Schepis TS, Simoni-Wastila L, McCabe SE. Prescription opioid and benzodiazepine misuse is associated with suicidal ideation in older adults. Int J Geriatr Psychiatry. 2019;34(1):122-29. Epub 2018/10/18.

18. Substance Abuse and Mental Health Services Administration (SAMHSA). Key substance use and mental health indicators in the United States: results from the 2016 National Survey on Drug Use and Health (HHS Publication No. SMA 17-5044, NSDUH Series H-52). Rockville, MD: Center for Behavioral Health Statistics and Quality, Substance Abuse and Mental Health Services; 2017.

19. Pearson CJ, Janz T, Ali J. Mental and substance use disorders in Canada. Ottawa, ON: Statistics Canada; 2013. Available from: https://www150.statcan.gc.ca/n1/en/pub/82-624-x/2013001/ article/11855-eng.pdf?st=6-7byDsm

20. Statistics Canada. Canadian Community Health Survey. Ottawa, ON: Statistics Canada; 2012. Available from: http://www23 .statcan.gc.ca/imdb-bmdi/instrument/3226_Q1_V9-eng.htm

21. Sullivan MA, Levin FR. Introduction. In: Sullivan MA, Levin FR, editors. Addiction in the older patient. Oxford, UK: Oxford University Press; 2016.

22. Han B, Polydorou S, Ferris R, et al. Demographic trends of adults in New York City opioid treatment programs - an aging population. Subst Use Misuse. 2015;50(13):1660-67. Epub 2015/11/20.

23. Larney S, Bohnert AS, Ganoczy D, et al. Mortality among older adults with opioid use disorders in the Veteran's Health Administration, 2000-2011. Drug Alcohol Depend. 2015;147:32-37. Epub 2015/01/13.

24. Brouwers MC, Kho ME, Browman GP, et al. AGREE II: advancing guideline development, reporting and evaluation in health care. CMAJ. 2010;182(18):E839-42. Epub 2010/07/07.

25. Guidelines International Network. Adaption Working Group. Adaption. 2016. Available from: https://www.g-i-n.net/working -groups/adaptation

26. Brozek JL, Akl EA, Compalati E, et al. Grading quality of evidence and strength of recommendations in clinical practice guidelines part 3 of 3 . The GRADE approach to developing recommendations. Allergy. 2011;66(5):588-95. Epub 2011/01/19.

27. Guyatt GH, Oxman AD, Vist GE, et al. GRADE: an emerging consensus on rating quality of evidence and strength of recommendations. BMJ. 2008;336(7650):924-26. Epub 2008/04/26.

28. Royal College of Psychiatrists (RCPsych). Substance misuse in older people: an information guide. London, UK: RCP; 2015.

29. World Health Organization (WHO). Guidelines for the psychosocially assisted pharmacological treatment of opioid dependence. Geneva: WHO; 2009. Available from: https://www .who.int/substance_abuse/publications/opioid_dependence _guidelines.pdf

30. American Society of Addiction Medicine (ASAM). The ASAM national practice guideline for the use of medications in the treatment of addiction involving opioid use. Chevy Chase, MD: ASAM; 2015.

31. U. S. Department of Veterans Affairs \& Department of Defense. VA\& DoD clinical practice guideline: management of substance use disorders (SUD). Washington, DC: The Department; 2015.
Available from: https://www.healthquality.va.gov/guidelines/ $\mathrm{mh} / \mathrm{sud} /$

32. Bruneau J, Ahamad K, Goyer ME, et al. Management of opioid use disorders: a national clinical practice guideline. CMAJ. 2018;190(9):E247-E57. Epub 2018/03/07.

33. Substance Abuse and Mental Health Services Administration (SAMHSA). Medications for opioid use disorder. For healthcare and addiction professionals, policymakers, patients, and families. (Treatment Improvement Protocol (TIP) Series 63). Rockville, MD: SAMHSA; 2018. Available from: https://store .samhsa.gov/system/files/sma18-5063fulldoc.pdf

34. The College of Physicians \& Surgeons of Ontario (CPSO). Methadone maintenance treatment: program standards and clinical guidelines. Toronto, ON: The College of Physicians and Surgeons of Ontario; 2011. Available from: https:// www.researchgate.net/publication/271076438_Methadone Maintenance_Treatment_Program_Standards_and_Clinical Guidelines_College_of_Physicians_and_Surgeons_of_Ontario

35. BC Centre on Substance Use (BCCSU) \& BC Ministry of Health. A guideline for the clinical management of opioid use disorder. Vancouver, BC: The authors; 2017. Available from: http://www.bccsu.ca/wp-content/uploads/2017/06/BC-OUD -Guidelines_June2017.pdf

36. College of Physicians of Ireland. Health Service Executive (HSE). Clinical guidelines for opioid substitution treatment. Dublin, Ireland: HSE; 2016. Available from: https://www.hse. ie/eng/services/publications/primary/clinical-guidelines-for -opioid-substitution-treatment.pdf

37. College of Physicians and Surgeons of British Columbia (CPSBC). Professional standards and guidelines: safe prescribing of drugs with potential for misuse/diversion. Vancouver, BC: The College; 2016. Available from: https://www.csam-smca .org/wp-content/uploads/2016/11/PSG-Safe-Prescribing.pdf

38. Royal Australian College of General Practitioners (RACGP). Prescribing drugs of dependence in general practice-Part C. East Melbourne, Australia: RACGP; 2017. Available from: https://www.racgp.org.au/download/Documents/Guidelines/ Opioid/Opioid-Guide-Summary.PDF

39. Kahan M. Management of alcohol use disorders, opioid prescribing, and opioid use disorders in primary care: a pocket reference for family physicians. Toronto, ON: Women's College Hospital; 2016. Available from: https://www.porticonetwork. ca/documents/324069/365598/PCP+ pocket + guide/279a0dedd3a3-4173-9f5c-52c6190baab5

40. Lingford-Hughes AR, Welch S, Peters L, et al. British Association of Psychopharmacology (BAP) updated guidelines: evidence-based guidelines for the pharmacological management of substance abuse, harmful use, addiction and comorbidity: recommendations from BAP. J Psychopharmacol. 2012;26(7):899-52. Epub 2012/05/26.

41. Canadian Centre on Substance Use and Addiction (CCSA). Awareness to recovery care pathway for treatment of older adults (65 and older) experiencing psychoactive prescription drug harms. Ottawa, ON: CCSA; 2016. Available from: http:// www.ccsa.ca/Resource\%20Library/CCSA-Care-Pathways-Older -Adult-Prescription-Drug-Treatment-Online-2016-en.pdf

42. Carew AM, Comiskey C. Treatment for opioid use and outcomes in older adults: a systematic literature review. Drug Alcohol Depend. 2018;182:48-57. Epub 2017/11/15. 


\section{RIEB: OPIOID USE DISORDER GUIDELINES}

43. Hassell C, Wilkins K, Trevisan LA. Pharmacology of geriatric substance use disorders: considerations and future directions. Curr Treat Options Psychiatry. 2017;4(1):102-15.

44. Le Roux C, Tang Y, Drexler K. Alcohol and opioid use disorder in older adults: neglected and treatable illnesses. Curr Psychiatry Rep. 2016;18(9):87. Epub 2016/08/05.

45. Loreck D, Brandt NJ, DiPaula B. Managing opioid abuse in older adults: clinical considerations and challenges. J Gerontol Nurs. 2016;42(4):10-15. Epub 2016/03/31.

46. Maree RD, Marcum ZA, Saghafi E, et al. A systematic review of opioid and benzodiazepine misuse in older adults. Am J Geriatr Psychiatry. 2016;24(11):949-63. Epub 2016/10/19.

47. Burgos-Chapman I, Trevisan L, Sevarino K. Abuse of opioids and prescription medications. In: Sullivan M, Levin FR, editors. Addiction in the older patient. London: Oxford University Press; 2016. p. 105-37.

48. DeVido J, Hirsch CH, Sanger N, et al. Substance use disorders in later life. In: Hategan A, Bourgeois JA, Hirsch CH, et al., editors. Geriatric psychiatry: a case-based textbook. New York, NY: Springer International Publishing; 2018. p. 319-43.

49. Bhatia U, Nadkarni A, Murthy $\mathrm{P}$, et al. Recent advances in treatment for older people with substance use problems: an updated systematic and narrative review. Eur Geriatr Med. 2015;6(6):580-86.

50. Busse JS, Craigie S, Juurlink DN, et al. Guideline for opioid therapy and chronic noncancer pain. CMAJ. 2017;189(18):E659E66. Epub 2017/05/10.

51. Centres for Disease Control \& Prevention. CDC guideline for prescribing opioids for chronic pain-United States, 2016. MMWR. 2016;65(1):1-49. Epub 2016/03/18.

52. Chou R, Turner JA, Devine EB, et al. The effectiveness and risks of long-term opioid therapy for chronic pain: a systematic review for a National Institutes of Health Pathways to Prevention Workshop. Ann Intern Med. 2015;162(4):276-86. Epub 2015/01/13.

53. Health Quality Ontario. Opioid prescribing for acute paincare of people 15 years and over. Toronto, ON: HQO; 2018. Available from: https://www.hqontario.ca/portals/0/documents/ evidence/quality-standards/qs-opioid-acute-pain-clinician -guide-en.pdf

54. Alam A, Gomes $\mathrm{T}$, Zheng $\mathrm{H}$, et al. Long-term analgesic use after low-risk surgery: a retrospective cohort study. Arch Intern Med. 2012;172(5):425-30. Epub 2012/03/14.

55. Shah A, Hayes C, Martin BC. Characteristics of initial prescription episodes and likelihood of long-term opioid use-United States, 2006-2015. Washington DC: Centres for Disease Control; 2017. Available from: https:/www.cdc.gov/mmwr/volumes/ 66/wr/mm6610a1.htm

56. Krebs EE, Gravely A, Nugent S, et al. Effect of opioid vs nonopioid medications on pain-related function in patients with chronic back pain or hip or knee osteoarthritis pain: The SPACE randomized clinical trial. JAMA. 2018;319(9):872-82.

57. Abdulla A, Bone M, Adams N, et al. Evidence-based clinical practice guidelines on management of pain in older people. Age Ageing. 2013;42(2):151-53. Epub 2013/01/22.

58. Griessinger N, Sittl R, Likar R. Transdermal buprenorphine in clinical practice - a post-marketing surveillance study in 13179 patients. Curr Med Res Opinion. 2005;21(8):1147-56.

59. Government of Canada. Ministry of Health. Reporting of loss or theft of controlled substances, precursors. Ottawa, ON:
Ministry of Health, Government of Canada; 2019 [cited 2019 February 11]. [Document \#: CS-GD-005]. Available from: https://www.canada.ca/en/health-canada/services/publications/ healthy-living/loss-theft-controlled-substances-precursors.html

60. Carman T, Adhopia V. More than half a million prescription drugs are stolen each year-and most are opioids. CBC Online. 2018 Jun 27. CBC Investigates section. Accessed 2019 February 11. Available from: https://www.cbc.ca/news/canada/ missing-drugs-pharmacies-part1-1.4708041

61. Canadian Pharmacists Association. Opioid action plan. Ottawa, ON: CPA; 2016. Available from: https://www.pharmacists.ca/cpha -ca/assets/File/cpha-on-the-issues/CPhA_OpioidActionPlan -18Nov16.pdf

62. Busse JW, Wang L, Kamaleldin M, et al. Opioids for chronic noncancer pain: a systematic review and meta-analysis. JAMA. 2018;320(23):2448-60.

63. Rx Files. Tapering opioids: how to explore and pursue the option for patients who stand to benefit [online article]. 2018. Available from: https://www.rxfiles.ca/rxfiles/uploads/documents/ Opioid-Tapering-Newsletter-Compilation.pdf

64. Michael G. DeGroote National Pain Centre. Opioid ManagerLogin/Download [website]. Hamilton, ON: MacMaster University; 2019. Available from: http://nationalpaincentre.mcmaster.ca/ opioidmanager/opioid_manager_download.html?appSession= 18T6QC7XCFD8476F3PE1SF12D37O85D82Z4133C6E1977O 1EV8K05O4U4048KEQ517C9SCJ67L669895RED6E13OPX 4VPUBCCO1HNP1I263NPHTCR7RA11LOEA83D33P

65. Berna C, Kulich RJ, Rathmell JP. Tapering long-term opioid therapy in chronic noncancer pain: evidence and recommendations for everyday practice. Mayo Clin Proc. 2015;90(6):828-42.

66. Health Quality Ontario. Opioid use disorder (opioid addiction): care of people 16 years of age and older: Toronto, ON: HQOntario; n.d. [cited 2019 May 24]. Available from: https://www .hqontario.ca/Evidence-to-Improve-Care/Quality-Standards/ View-all-Quality-Standards/Opioid-Use-Disorder/Quality -Statement-9-Tapering-Off-of-Opioid-Agonist-Therapy

67. Nosyk B, Sun H, Evans E, et al. Defining dosing pattern characteristics of successful tapers following methadone maintenance treatment: results from a population-based retrospective cohort study. Addiction. 2012;107(9):1621-29. Epub 2012/03/06.

68. Walley AY, Doe-Simkins M, Quinn E, et al. Opioid overdose prevention with intranasal naloxone among people who take methadone. J Subst Abuse Treat. 2013;44(2):241-47. Epub 2012/09/18.

69. Walley AY, Xuan Z, Hackman HH, et al. Opioid overdose rates and implementation of overdose education and nasal naloxone distribution in Massachusetts: interrupted time series analysis. BMJ. 2013;346:f174. Epub 2013/02/02.

70. Costello M, Thompson S. Preventing opioid misuse and potential abuse: the nurse's role in patient education. Pain Manag Nurs. 2015;16(4):515-19. Epub 2014/12/17.

71. Manworren RC, Gilson AM. Nurses' role in preventing prescription opioid diversion. Am J Nurs. 2015;115(8):34-40. Epub 2015/07/18.

72. Jukiewicz DA, Alhofaian A, Thompson Z, et al. Reviewing opioid use, monitoring, and legislature: nursing perspectives. Int J Nurs Sci. 2017;4(4):430-36.

73. Bastos FI, Strathdee SA. Evaluating effectiveness of syringe exchange programmes: current issues and future prospects. Soc Sci Med. 2000;51(12):1771-82. Epub 2000/12/29. 


\section{RIEB: OPIOID USE DISORDER GUIDELINES}

74. Kerr T, Tyndall M, Li K, Montaner J, et al. Safer injection facility use and syringe sharing in injection drug users. Lancet. 2005;366(9482):316-18. Epub 2005/07/26.

75. $\mathrm{Ng}$ J, Sutherland C, Kolber MR. Does evidence support supervised injection sites? Can Fam Physician. 2017;63(11):866. Epub 2017/11/16.

76. Rieb L. Assessment. In: Heron A, Brennen T, editors. The ASAM essentials of addiction medicine, $3^{\text {rd }}$ edition. Philadelphia, PA: Wolters Kluwer/Lippincott Williams \& Wilkins; 2019.

77. Schonfeld L, Hazlett RW, Hedgecock DK, et al. Screening, brief intervention, and referral to treatment for older adults with substance misuse. Am J Public Health. 2015;105(1):205-11. Epub 2014/05/17.

78. Draper B, Ridley N, Johnco C, et al. Screening for alcohol and substance use for older people in geriatric hospital and community health settings. Int Psychogeriatr. 2015;27(1):157-66. Epub 2014/09/24.

79. Park J, Clement R, Lavin R. Factor structure of pain medication questionnaire in community-dwelling older adults with chronic pain. Pain Pract. 2011;11(4):314-24. Epub 2010/ $12 / 15$.

80. Becker WC, Fraenkel L, Edelman EJ, et al. Instruments to assess patient-reported safety, efficacy, or misuse of current opioid therapy for chronic pain: a systematic review. Pain. 2013;154(6):905-16. Epub 2013/04/23.

81. Wu LT, Blazer DG. Illicit and nonmedical drug use among older adults: a review. J Aging Health. 2011;23(3):481-504. Epub 2010/11/19

82. Rao R, Crome I. Assessment in the older patient In: Sullivan MA, Levin FR, editors. Addiction in the older patient. Oxford, UK: Oxford University Press; 2016. p. 173-209.

83. Luoma JB, Twohig MP, Waltz T, et al. An investigation of stigma in individuals receiving treatment for substance abuse. Addict Behav. 2007;32(7):1331-46. Epub 2006/11/10.

84. Substance Abuse and Mental Health Services Administration (SAMHSA). Clinical guidelines for the use of Buprenorphine in the treatment of opioid addiction. (Treatment Improvement Protocol (TIP) Series 40). Rockville, MD: Center for Behavioral Health, Statistics and Quality, Substance Abuse and Mental Health Services; 2004. Available from: http://lib.adai.washington.edu/clearinghouse/downloads/TIP-40-Clinical-Guidelines -for-the-Use-of-Buprenorphine-in-the-Treatment-of-Opioid -Addiction-54.pdf

85. The ASAM Handbook of Addiction Medicine. New York, NY: Lippincott Williams \& Wilkins; 2015.

86. The ASAM Essentials of Addiction Medicine, 2nd ed. New York, NY: Lippincott Williams \& Wilkins; 2015.

87. The ASAM Principles of Addiction Medicine, 4th ed. Philidelphia, PA: Lippincott Williams \& Wilkins; 2009.

88. Gowing L, Farrell M, Ali R, et al. Alpha2-adrenergic agonists for the management of opioid withdrawal. Cochrane Database of Syst Rev. 2016(5).

89. Wright NM, Sheard L, Adams CE, et al. Comparison of methadone and buprenorphine for opiate detoxification (LEEDS trial): a randomised controlled trial. Br J Gen Pract. 2011;61(593):e772-80. Epub 2011/12/06.

90. Amato L, Davoli M, Minozzi S, et al. Methadone at tapered doses for the management of opioid withdrawal. Cochrane Database Syst Rev. 2013(2):Cd003409. Epub 2013/03/02.
91. Gowing L, Ali R, White JM, et al. Buprenorphine for managing opioid withdrawal. Cochrane Database Syst Rev. 2017(2):Cd002025. Epub 2017/02/22.

92. Hess M, Boesch L, Leisinger R, et al. Transdermal buprenorphine to switch patients from higher dose methadone to buprenorphine without severe withdrawal symptoms. Am J Addict. 2011;20(5):480-81. Epub 2011/08/16.

93. Hämmig R, Kemter A, Strasser J, et al. Use of microdoses for induction of buprenorphine treatment with overlapping full opioid agonist use: the Bernese method. Substance Abuse Rehab. 2016;7:99-105.

94. Campbell G, Hall WD, Peacock A, et al. Effect of cannabis use in people with chronic non-cancer pain prescribed opioids: findings from a 4-year prospective cohort study. Lancet Pub Health. 2018;3(7):e341-e50. Epub 2018/07/07.

95. Caputi TL, Humphreys K. Medical marijuana users are more likely to use prescription drugs medically and nonmedically. J Addict Med. 2018;12(4):295-99. Epub 2018/04/18.

96. Humphreys K, Saitz R. Should physicians recommend replacing opioids with cannabis? [Viewpoint] JAMA. 2019;321(7): 639-40. Epub 2019/02/02.

97. Fiellin DA, Schottenfeld RS, Cutter CJ, et al. Primary carebased buprenorphine taper vs maintenance therapy for prescription opioid dependence: a randomized clinical trial. JAMA Intern Med. 2014;174(12):1947-54. Epub 2014/10/21.

98. Mattick RP, Breen C, Kimber J, et al. Buprenorphine maintenance versus placebo or methadone maintenance for opioid dependence. Cochrane Database Syst Rev. 2014(2):CD002207. Epub 2014/02/07.

99. Pergolizzi J, Boger RH, Budd K, et al. Opioids and the management of chronic severe pain in the elderly: consensus statement of an International Expert Panel with focus on the six clinically most often used World Health Organization Step III opioids (buprenorphine, fentanyl, hydromorphone, methadone, morphine, oxycodone). Pain Pract. 2008;8(4):287-313. Epub 2008/05/28.

100. Rieb LM. Extended-release naltrexone overlooked in opioid use disorders guideline. Can Med Assoc J. 2018;190(28):E862.

101. Larochelle MR, Bernson D, Land T, et al. Medication for opioid use disorder after nonfatal opioid overdose and association with mortality: a cohort study. Ann Intern Med. 2018;169(3):137-45. Epub 2018/06/19.

102. Daitch D, Daitch J, Novinson D, et al. Conversion from highdose full-opioid agonists to sublingual buprenorphine reduces pain scores and improves quality of life for chronic pain patients. Pain Med. 2014;15(12):2087-94. Epub 2014/09/16.

103. Lee JD, Grossman E, Truncali A, et al. Buprenorphine-naloxone maintenance following release from jail. Subst Abuse. 2012;33(1):40-47.

104. Riggins DP, Cunningham CO, Ning Y, et al. Recent incarceration and buprenorphine maintenance treatment outcomes among human immunodeficiency virus-positive patients. Subst Abuse. 2017;38(3):297-302. Epub 2016/10/08.

105. Bozinoff N, DeBeck K, Milloy MJ, et al. Utilization of opioid agonist therapy among incarcerated persons with opioid use disorder in Vancouver, Canada. Drug Alcohol Depend. 2018;193:42-47. Epub 2018/10/20.

106. Lofwall MR, Walsh SL, Nunes EV, et al. Weekly and monthly subcutaneous buprenorphine depot formulations vs daily sublingual buprenorphine with naloxone for treatment of opioid 


\section{RIEB: OPIOID USE DISORDER GUIDELINES}

use disorder: a randomized clinical trial. JAMA Intern Med. 2018;178(6):764-73. Epub 2018/05/26.

107. Haight BR, Learned SM, Laffont CM, et al. Efficacy and safety of a monthly buprenorphine depot injection for opioid use disorder: a multicentre, randomised, double-blind, placebocontrolled, phase 3 trial. Lancet. 2019;393(10173):778-90. Epub 2019/02/23.

108. Ling W, Nadipelli VR, Solem CT, et al. Patient-centered outcomes in participants of a buprenorphine monthly depot (BUP-XR) double-blind, placebo-controlled, multicenter, phase 3 study. J Addict Med. 2019;13(6):442. Epub 2019/03/08.

109. Mattick RP, Breen C, Kimber J, et al. Methadone maintenance therapy versus no opioid replacement therapy for opioid dependence. Cochrane Database Syst Rev. 2009(3):CD002209. Epub 2009/07/10.

110. Firoz S, Carlson G. Characteristics and treatment outcome of older methadone-maintenance patients. Am J Geriatr Psychiatry. 2004;12(5):539-41.

111. Fareed A, Casarella J, Amar R, et al. Benefits of retention in methadone maintenance and chronic medical conditions as risk factors for premature death among older heroin addicts. J Psychiatr Pract. 2009;15(3):227-34. Epub 2009/05/23.

112. Guo S, Winslow M, Manning V, et al. Monthly take-home methadone maintenance regime for elderly opium-dependent users in Singapore. Ann Acad Med, Singapore. 2010;39(6):429-34. Epub 2010/07/14.

113. Rosen D, Smith ML, Reynolds 3rd CF. The prevalence of mental and physical health disorders among older methadone patients. Am J Geriatr Psychiatry. 2008;16(6):488-97. Epub 2008/06/03.

114. Substance use and older people. Crome I, Tzu L, Rao R, et al., editors. West Sussex, UK: John Wiley and Sons Inc.; 2015.

115. Martucci C, Panerai AE, Sacerdote P. Chronic fentanyl or buprenorphine infusion in the mouse: similar analgesic profile but different effects on immune responses. Pain. 2004;110(1-2):38592. Epub 2004/07/28.

116. Lee JD, Friedmann PD, Kinlock TW, et al. Extended-release naltrexone to prevent opioid relapse in criminal justice offenders. N Engl J Med. 2016;374(13):1232-42. Epub 2016/03/31.

117. Lee JD, Nunes Jr. EV, Novo P, et al. Comparative effectiveness of extended-release naltrexone versus buprenorphine-naloxone for opioid relapse prevention (X:BOT): a multicentre, openlabel, randomised controlled trial. Lancet. 2018;391(10118): 309-18. Epub 2017/11/14.

118. Minozzi S, Amato L, Vecchi S, et al. Oral naltrexone maintenance treatment for opioid dependence. Cochrane Database Syst Rev. 2011(4):CD001333. Epub 2011/04/15.

119. Tanum L, Solli KK, Latif ZE, et al. Effectiveness of injectable extended-release naltrexone vs daily buprenorphine-naloxone for opioid dependence: a randomized clinical noninferiority trial. JAMA Psychiatry. 2017;74(12):1197-205. Epub 2017/10/20.

120. Kunøe N, Opheim A, Solli KK, et al. Design of a randomized controlled trial of extended-release naltrexone versus daily buprenorphine-naloxone for opioid dependence in Norway (NTX-SBX). BMC Pharmacol Toxicol. 2016;17(1):18.

121. Hassan AN, Howe AS, Samokhvalov AV, et al. Management of mood and anxiety disorders in patients receiving opioid agonist therapy: review and meta-analysis. Am J Addict. 2017;26(6):551-63. Epub 2017/07/05.
122. Sun EC, Dixit A, Humphreys K, et al. Association between concurrent use of prescription opioids and benzodiazepines and overdose: retrospective analysis. BMJ. 2017;356:j760. Epub 2017/03/16.

123. Hernandez I, He M, Brooks MM, et al. Exposure-response association between concurrent opioid and benzodiazepine use and risk of opioid-related overdose in medicare part $\mathrm{d}$ beneficiaries. JAMA Network Open. 2018;1(2):e180919-e.

124. Saulle R, Vecchi S, Gowing L. Supervised dosing with a longacting opioid medication in the management of opioid dependence. Cochrane Database Syst Rev. 2017(4):Cd011983. Epub 2017/04/28.

125. AGS Panel on Persistent Pain in Older Persons. The management of persistent pain in older persons. J Am Geriatr Soc. 2002;50(6 Suppl):S205-24. Epub 2002/06/18.

126. AGS Panel on Pharmacological Management of Persistent Pain in Older Persons. Pharmacological management of persistent pain in older persons [reprint]. Pain Med. 2009;10(6):1062-83. Epub 2009/09/12.

127. Gupta DK, Avram MJ. Rational opioid dosing in the elderly: dose and dosing interval when initiating opioid therapy. Clin Pharmacol Therapeut. 2012;91(2):339-43. Epub 2011/12/30.

128. Malec M, Shega JW. Pain management in the elderly. Medical Clin. 2015;99(2):337-50.

129. Denton FT, Spencer BG. Chronic health conditions: changing prevalence in an aging population and some implications for the delivery of health care services. Can J Aging. 2010;29(1):11-21. Epub 2010/03/06.

130. Busse JW, Juurlink D, Guyatt GH. Addressing the limitations of the CDC guideline for prescribing opioids for chronic noncancer pain. CMAJ. 2016;188(17-18):1210-11. Epub 2016/ $11 / 23$.

131. Furlan AD, Reardon R, Weppler C. Opioids for chronic noncancer pain: a new Canadian practice guideline. CMAJ. 2010;182(9):923-30.

132. Guerriero F. Guidance on opioids prescribing for the management of persistent non-cancer pain in older adults. World J Clin Cases. 2017;5(3):73-81. Epub 2017/03/30.

133. White AM, Philogene GS, Fine L, et al. Social support and self-reported health status of older adults in the United States. Am J Public Health. 2009;99(10):1872-78. Epub 2009/08/22.

134. Newson RS, Boelen PA, Hek K, et al. The prevalence and characteristics of complicated grief in older adults. $J$ Affect Disord. 2011;132(1-2):231-38. Epub 2011/03/15.

135. Amato L, Minozzi S, Davoli M, et al. Psychosocial combined with agonist maintenance treatments versus agonist maintenance treatments alone for treatment of opioid dependence. Cochrane Database Syst Rev. 2011(10):CD004147. Epub 2011/10/07.

136. Dugosh K, Abraham A, Seymour B, et al. A systematic review on the use of psychosocial interventions in conjunction with medications for the treatment of opioid addiction. J Addict Med. 2016;10(2):93-103. Epub 2016/01/26.

137. Khodabande F, Kahani S, Shadnia S, et al. Comparison of the efficacy of methadone maintenance therapy vs. narcotics anonymous in the treatment of opioid addiction: a 2-year survey. Int J Pharmacol. 2012;8(5):445-49.

138. Galanter M. Combining medically assisted treatment and Twelve-Step programming: a perspective and review. Am J Drug Alcohol Abuse. 2018;44(2):151-59. Epub 2017/04/08. 


\section{RIEB: OPIOID USE DISORDER GUIDELINES}

139. Grant S, Colaiaco B, Motala A, et al. Mindfulness-based relapse prevention for substance use disorders: a systematic review and meta-analysis. $J$ Addict Med. 2017;11(5):386-96. Epub 2017/07/21.

140. Griffith JD, Rowan-Szal GA, Roark RR, et al. Contingency management in outpatient methadone treatment: a metaanalysis. Drug Alcohol Depend. 2000;58(1-2):55-66. Epub 2000/02/11.

141. Prendergast M, Podus D, Finney J, et al. Contingency management for treatment of substance use disorders: a meta-analysis. Addiction. 2006;101(11):1546-60. Epub 2006/10/13.

142. Olmstead TA, Petry NM. The cost-effectiveness of prize-based and voucher-based contingency management in a population of cocaine- or opioid-dependent outpatients. Drug Alcohol Depend. 2009;102(1-3):108-15. Epub 2009/03/28.

143. Benishek LA, Dugosh KL, Kirby KC, et al. Prize-based contingency management for the treatment of substance abusers: a meta-analysis. Addiction. 2014;109(9):1426-36. Epub 2014/04/23.

144. Downey KK, Helmus TC, Schuster CR. Treatment of heroindependent poly-drug abusers with contingency management and buprenorphine maintenance. Experiment Clin Psychopharmacol. 2000;8(2):176-84.

145. Petry NM, Martin B. Low-cost contingency management for treating cocaine- and opioid-abusing methadone patients. J Consult Clin Psychol. 2002;70(2):398-405.

146. Chopra MP, Landes RD, Gatchalian KM, et al. Buprenorphine medication versus voucher contingencies in promoting abstinence from opioids and cocaine. Exp Clin Psychopharmacol. 2009;17(4):226-36. Epub 2009/08/06.

147. Ling W, Hillhouse M, Ang A, et al. Comparison of behavioral treatment conditions in buprenorphine maintenance. Addiction. 2013;108(10):1788-98. Epub 2013/06/06.

148. Mamakwa S, Kahan M, Kanate D, et al. Evaluation of 6 remote First Nations community-based buprenorphine programs in northwestern Ontario: retrospective study. Can Fam Physician. 2017;63(2):137-45. Epub 2017/02/18.

149. Rao R, Roche A. Substance misuse in older people [editorial]. BMJ. 2017;358:j3885.

150. Cicero TJ, Surratt HL, Kurtz S, et al. Patterns of prescription opioid abuse and comorbidity in an aging treatment population. J Subst Abuse Treat. 2012;42(1):87-94. Epub 2011/08/13.

151. Huhn AS, Strain EC, Tompkins DA, et al. A hidden aspect of the U.S. opioid crisis: rise in first-time treatment admissions for older adults with opioid use disorder. Drug Alcohol Depend. 2018;193:142-47. Epub 2018/11/02.
152. Bao YP, Liu ZM, Epstein DH, et al. A meta-analysis of retention in methadone maintenance by dose and dosing strategy. Am J Drug Alcohol Abuse. 2009;35(1):28-33. Epub 2009/01/20.

153. Fareed A, Vayalapalli S, Casarella J, et al. Effect of buprenorphine dose on treatment outcome. J Addict Dis. 2012;31(1):8-18. Epub 2012/02/24.

154. Alford DP, LaBelle CT, Richardson JM, et al. Treating homeless opioid dependent patients with buprenorphine in an office-based setting. J Gen Intern Med. 2007;22(2):171-76. Epub 2007/03/16.

155. Neri S, Bruno CM, Pulvirenti D, et al. Randomized clinical trial to compare the effects of methadone and buprenorphine on the immune system in drug abusers. Psychopharmacol. 2005;179(3):700-04. Epub 2005/04/05.

156. Weiss L, Netherland J, Egan JE, et al. Integration of buprenorphine/naloxone treatment into HIV clinical care: lessons from the BHIVES collaborative. J Acq Imm Defic Syndrom. 2011;56(Suppl 1):S68-S75. Epub 2011/03/01.

157. Giftos J, Tesema L. When less is more: reforming the criminal justice response to the opioid epidemic. Judges $J .2018$; 57(1):28-31.

158. Cheverie M, Johnson S, Moser A. Buprenorphine maintenance treatment for opioid dependent inmates. Ottawa, ON: Corrections Canada; 2010. Available from: https://www.csc-scc.gc.ca/ 005/008/092/b48-eng.pdf

159. Magura S, Lee JD, Hershberger J, et al. Buprenorphine and methadone maintenance in jail and post-release: a randomized clinical trial. Drug Alcohol Depend. 2009;99(1-3):222-30. Epub 2008/10/22.

160. Canadian Centre on Substance Use and Addiction. Canadian substance use costs and harms 2007-2014. Ottawa, ON: CCSA; 2018. Available from: http://www.ccsa.ca/Resource $\% 20$ Library/CSUCH-Canadian-Substance-Use-Costs-Harms -Report-2018-en.pdf

161. Korownyk C, Perry D, Ton J, et al. Managing opioid use disorder in primary care: PEER simplified guideline. Can Fam Physician. 2019;65(5):321-30. Epub 2019/05/16.

162. Krebs E, Enns B, Evans E, et al. Cost-effectiveness of publicly funded treatment of opioid use disorder in California. Ann Intern Med. 2018;168(1):10-19. Epub 2017/11/22.

Correspondence to: Launette Rieb, MD, MSc, CCFP(AM), FCFP, DABAM, Clinical Associate Professor, Department of Family Practice, UBC, CBI Health Centre, 201-3150 East 54th Ave., Vancouver, BC, CANADA V5S 1Z1

E-mail: Launette.Rieb@ubc.ca 